\title{
Lexus Lanes or Corolla Lanes? Spatial Use and Equity Patterns on the I-394 MnPASS Lanes
}

\author{
March 2008
}

Tyler M. Patterson
Department of Civil Engineering
University of Minnesota
500 Pillsbury Drive SE
Minneapolis, MN 55455
patte243@umn.edu
503.679 .4060

\author{
Dr. David M. Levinson \\ Department of Civil Engineering \\ University of Minnesota \\ 500 Pillsbury Drive SE \\ Minneapolis, MN 55455 \\ dlevinson@umn.edu \\ 612.625.6354
}

\begin{abstract}
A 2004-2006 longitudinal panel survey of I-394 residents found support levels at over 60 percent for the congestion priced High Occupancy Toll (HOT) lane, known to the Twin Cities as MnPASS. This number varies only slightly when sorted by income levels, gender, and education levels, suggesting that the arrangement is perceived as equitable. However, people with higher incomes use the system more often and thereby capitalize on the direct benefit more often, a finding consistent with other studies. Previous research has not revealed whether higher incomes actually cause people to use the MnPASS option more often or whether HOT lanes have simply been built along high income corridors, such as I-394. This paper aims to separate the effects of income and location on use to provide a more robust understanding of equity concerns. Using data provided by the Minnesota Department of Transportation, Heteroskedasticity-Consistent Method 3 (HC3) regressions, this paper suggests that location and income both explain HOT lane use.
\end{abstract}




\section{Introduction}

Congestion pricing schemes are growing in popularity around the world. As cities grapple with ballooning demand for roadway space, governments are harnessing the power of the market to more efficiently allocate scarce infrastructure resources. Few High Occupancy Toll (HOT) lanes exist within the United States and while all have been operational successes, little empirical evidence exists regarding their equity impacts. A 2004-2006 longitudinal panel survey of I-394 corridor residents found support levels at over 60 percent for the congestion priced HOT lane, known in Minnesota as MnPASS. This number varied only slightly when sorted by income levels, gender, and education levels, suggesting that the arrangement is perceived as equitable. However, people with higher incomes use the system more often and thereby capitalize on the direct benefit more often, a finding consistent with other studies around the country. This paper seeks to separate the effects of income and location to provide a more robust understanding of the relationship between these two factors that are used to evaluate equity.

Traditionally toll roads were intended to finance infrastructure. Some toll roads have been converted to use congestion varying toll levels, rather than fixed tolls. This enables more efficient use of the infrastructure by allocating space to those who value their time the most and avoiding lost capacity of the infrastructure due to congestion (Vickrey 1969; Small, Winston et al. 1989). In recent years a few High Occupancy Vehicle (HOV) lanes within the United States have been converted to congestion pricing, opening the lanes which were underused to additional toll paying traffic. These HOT lanes hope to raise enough revenue to pay back their operating and capital costs and generate a surplus (Federal Highway Administration 2007). Although other HOT lanes exist, they remain a new enough concept that there is little empirical information on their impacts for transportation planners and policy makers to use when making decisions about similar types of congestion pricing projects. The uniqueness of this tolling situation has prompted many critics to react viscerally, arguing that these "Lexus Lanes" benefit only the wealthy and that the gains in infrastructure efficiency are insufficient to counteract the uneven distribution of benefits. (The term "Lexus Lanes" is attributed to California State Senator Thomas Hayden (Moxley 2000).) These equity concerns, if left unaddressed, may render this innovative concept's potential stunted. Investigating this equity claim is the focus of this paper.

This paper tests two primary hypotheses. (1) The I-394 MnPASS HOT lane is really a "Lexus Lane." People with higher income use the HOT lanes more frequently than those with lower incomes. This investigation attempts to ascertain how strong a factor income is in explaining lane use, among other equity measures. (2) Within a defined travelshed, travelers living farther from downtown Minneapolis will use the HOT lane more often. In addition to the hypotheses, this paper strives to contribute to the general knowledge of the workings of the HOT lanes and put forth two possible methodologies to be used in the context of similar studies, one relating to other measurements of equity and the other relating to location measurements. 
The paper begins with a review of the extant HOT Lane projects, including details of the MnPASS system studied here. This is followed by a description of the data used in the study. Descriptive statistics, regression models, and discussion of the results follow in turn.

\section{HOT Lane Projects Surveys}

At the time the MnPASS lane opened, there were four operating HOT Lanes, located in Orange County, California, San Diego, California, Houston, Texas, and Minneapolis-St. Paul, Minnesota. Since then, lanes have opened in Denver, Colorado and Salt Lake City, Utah. Studies of the first four systems are described in order.

\subsection{SR-91 Orange County}

SR-91 opened in December 1995 as the first value-priced roadway in the United States. The 10-mile $(16 \mathrm{~km})$ stretch connects the employment centers of Orange County and southern L.A. County through the addition of two express lanes in each direction. The lanes are separated from the general-purpose lanes by a "soft" barrier consisting of painted lines and pylons. Heavy commercial vehicles are not permitted on the route and carpools travel at a discounted rate. No tollbooths exist, only electronic gantries; users are required to purchase and display small electronic transponders.

A telephone surveys of approximately 500 drivers whose license plates had been captured while traveling on SR-91 the previous week asked a series of questions in the fall of 1995 (prior to the opening) in regards to tolling. Approval rating for the tolling of roads came back at around 65 percent across user groups. When asked about the variable nature of the toll price, respondents were significantly less enthused with an approval of about 45 percent (Sullivan 1998).

Sullivan (2000) found that as incomes increased, the number of people who had never used the express lane decreased. However, Sullivan also learned that of the lane's frequent users, little variation existed between income levels between $\$ 40,000$ and $\$ 100,000$. Over $\$ 100,000$, the use frequency did increase significantly and stood nearly twice as large as those $\$ 40,000$ to $\$ 100,000$ users. Despite limitations due to the sample size, this difference was statistically significant at the 90 percent confidence interval.

\subsection{I-15 San Diego}

The successes on SR-91 contributed to the utilization of road-pricing solutions on congested I-15 in San Diego (Regan 2004). In December 1996, (one year after the opening on the SR-91 facility) a demonstration project began on an 8.5 mile $(14 \mathrm{~km})$ stretch of I-15. The underutilized reversible carpool lanes were opened to SOVs through a tolling system, transforming them into HOT lanes. The reversible lanes, which are separated from the general-purpose lanes by a concrete barrier, allow inbound traffic in the morning hours and outbound traffic in the evening through one point-of-entry and one point-of-departure. 
In the first phase, SOV drivers purchased monthly passes (dubbed ExpressPass) that permitted unlimited use of the facility, while carpools remained within the lanes without a charge. In March 1998, the second phase introduced windshield-mounted transponders for automatic vehicle identification of SOV drivers wishing to use "FasTrak." The transponders allowed a change in the toll collection method from monthly permits to a per-trip fee that was based on congestion levels. When congestion appeared, variable tolls charged to SOVs rose to maintain free-flow conditions within the lanes. Carpools continued to travel free of charge (Brownstone, Ghosh et al. 2002).

A random dial telephone survey of 400 homes, three focus groups, and 141 face-to-face interviews with transit riders were employed to extract the public's attitude prior to the implementation of the changes. Approximately 70 percent of those polled expressed at least "somewhat" favorable view of tolling. Opposition by carpoolers stood at over 70 percent expressing at least a "somewhat" opposed view of tolling (Wilbur Smith and Associates 1996).

The results of a panel survey found that FasTrak customers differed from other users of I15 in seven significant ways: more highly educated, mostly 35-54 years old, homeowners, household incomes over $\$ 80,000$, more likely to be female, members of two vehicle households, and use the one onramp to the system, Ted Williams Parkway (Supernak 1998; Supernak 1998).

During the second wave of the study, in spring 1998, following the switch to variable pricing and FasTrak, researchers replaced those who refused a second interview or could not be found or moved away with similar category users. Thirty-four percent (516 of 1,501) of the participants had to be replaced for Wave 2; similar attrition took place between Waves 2 and 3. As a whole, commuters recognized a reduction in commute time. While carpooling remained fairly constant on the control corridor (I-8), it increased on I-15 (Supernak 2000).

\subsection{Houston HOT Lane (QuickRide Program)}

Although the reversible HOT lane on the Katy Freeway is not dynamically priced and does not allow SOV drivers, the equity issues are similar to warrant discussion. In January 1998, two passenger vehicles (HOV-2) were permitted to enter the lane for a fee of $\$ 2$, while vehicles with three or more passengers continued to travel for free.

Burris and Hannay (2003), examined equity issues associated with the lane, comparing surveys sent to QuickRide enrollees and non-participants. They found that people significantly overstated their use of the program; however, this overstatement did not vary across the socio-economic characteristics. Interestingly, the study also uncovered evidence that use of the lane varied little depending on household income, occupation, household size, and income. The authors pointed to the requirement of a credit card for opening an account and other cost increasing fees as possible pressures prohibiting many lower-income potential users from joining the program. They concluded by proclaiming that, "no individuals were worse off due to the program". 


\subsection{I-394 MnPASS Minnesota}

Minnesota implemented High-Occupancy Toll (HOT) lanes on Interstate 394 from downtown Minneapolis through its western suburbs in May 2005. Branded as the I-394 MnPASS lanes, they operate using electronic toll collection, where commuters purchase electronic transponders and drive under toll collection gantries, which automatically debit a user account. Tolls are variable and determined not by the number of vehicles in the general purpose lanes, but rather by the number of vehicles in the HOT lanes. The more congested the HOT lanes becomes, the higher the toll. Electronic signs update commuters as toll prices fluctuate; however, the price paid on entry remains valid for the entire commute. Typical peak period tolls run $\$ 1$ to $\$ 4$, but can reach as high as $\$ 8$ during periods of unusual congestion. The system runs 11 miles $(18 \mathrm{~km})$ in length and is divided into two sections: west of MN-100, the MnPASS lanes are separated from the general purpose lanes by painted double white strip lines with multiple points of entry; and east of highway 100, the 2 lanes operate in the barrier-separated reversible section, with access points only at each end, as shown in Figure 1 and Map 1. By design, toll revenues pay for the operating costs and any surplus, after repaying the capital costs, are legislated to be reinvested into the corridor. The goal of the system is to maintain the freeflow nature of the managed lane and improve the overall effectiveness of the corridor. By imposing a value on the amount of time saved, those with a high value of time (e.g. late for an airplane) pay for a reliable congestion-free trip. Those that do not pay still benefit indirectly in other ways (Cambridge Systematics 2002; Minnesota Department of Transportation 2005; Minnesota Department of Transportation 2005). See Figure 1 for an overview of the area.

Table 1 indicates that little variation in support for the I-394 MnPASS project exists between demographic groups, including income, gender, and education level. Of the corridor residents surveyed, only 20 percent of households making less than $\$ 50,000$ annually thought the idea of allowing SOVs into the carpool lanes a bad one. This observation contradicts the Lexus Lane argument, but is not sufficient to rule-out equity concerns. Map 2 displays income levels by zip code, establishing that the I-394 corridor serves some of the region's wealthiest residents. The challenge of this paper is to disentangle location and income variables to draw conclusions about equity concerns.

\section{Data}

The analysis relies primarily on a database of every MnPASS trip made from May 2005 (opening day) - July 2007. Permission was granted by the Minnesota Department of Transportation (Mn/DOT), and the database was sent by the firm operating the MnPASS system. The dataset includes a unique identification for every trip, transponder identification number, zip code of billing addresses, time entered and exited the lane, entry and exit gantry ID, and amount of toll paid. Nearly 2 million MnPASS trips were made during the first two years, averaging roughly 3,500 trips per day. Additionally, information regarding median household income and population were extracted for the corresponding zip codes from the 2000 US Census. 


\section{Description}

\subsection{Generating and Mapping}

Income and population data by zip code were downloaded from the US Census and merged with ArcMap projection available from MetroGIS. There were 162 zip codes within the metropolitan area, and 243 zip codes to which bills were sent. The 243 zip codes included codes from as far away as California. Since this project used billing zip codes as a proxy measure for origin/destination location, codes outside the Twin Cities 7 county area were removed as outliers. Although the 162 included zip codes within the metropolitan area comprising only 67 percent of the billing zip codes, they accounted for 94 percent of the transponders $(12,410$ out of 13,207$)$ and 99.97 percent of the MnPASS trips $(1,867,307$ out of $1,846,784)$. Of the 162 metro zip codes, 3 zip codes were missing US Census data (55111, 55450, and 55054). Combined, those zip codes had 3 transponders and 477 trips; they were removed as well. Of the remaining 159 zip codes, 21 did not take any trips at all and were located primarily in Washington County, east of the metro area. Map 1 provides an overview of the zip codes, water bodies, and roads within the study area. By July 2007, nearly 13,000 transponders had been leased.

\subsection{Characteristics of Travelshed and Existing Use Patterns}

The I-394 travelshed was loosely defined as a wedge that centers on Minneapolis and fanned out from between MN-55 to the north and MN-7 to the south. Inside the beltway (east of the I-394 / I-494 interchange) are first and second ring suburbs with moderate median household incomes, between $\$ 36,000$ and $\$ 62,000$. West of I-494, median household incomes grew substantially and hovered between $\$ 62,000$ and $\$ 95,000$, see Map 2. All classifications contained within the maps used Jenks Natural Breaks, a classification method that minimizes the differences within each category and maximizes the differences between categories (Jenks 1967).

Map 3 displays the population densities of the travelshed and surrounding area. The density decreased as one travels farther from Minneapolis's central business district (CBD) and dropped to its lowest density classification west of I-494. This decreasing density pattern is known to any casual observer of urban form, but is consistent with Clark's finding that residential density decreases as distance from the urban core grows (1951).

Map 4 presents the density of transponders per 1,000 persons. The billing zip code served as a proxy measure for home location, although some suspected to be work addresses were removed in subsequent sections. These omissions were noted. The map articulated that the area west of the I-394 / I-494 interchange was the most heavily saturated with transponder lessees, which coincided with the decrease in density and the increase in median household income. Of note was the sliver of light orange zip codes running parallel to and on the east side of MN-100. Recall that I-394's reversible section from MN-100 to downtown Minneapolis had only one entrance and one exit: MN-100 and Minneapolis. People living in this void were unable to access the reversible would not be expected to use the system to get downtown. 
Maps 5 and 6 are similar to the transponder density map (Map 4), displaying the total number of trips taken by transponders from those locations. Aside from the large number of trips from the far western suburbs, there were also a large number of trips taken from residents along the $\mathrm{MN}-100$ corridor, especially to the south.

Tables 2 and 3 present crosstabulations of the number of trips made between the corridor locations. Approximately 993,000 trips were taken in the morning period (6am - 10am) (Minnesota Department of Transportation 2005). Regardless of entry point, 91 percent of trips exited the system at the terminus in Minneapolis. Of people who exited in Minneapolis, 46 percent only used the reversible section, while 37 percent entered at either of the most western gantries (I-494 and Ridgedale). Only 17 percent entered at the middle two gantries. This suggests that the greatest time savings is found within the reversible section. One possible explanatory factor for the inconsistent entries was the way the system was priced. I-394 MnPASS lanes were divided into two sections and the same price was paid regardless of entry point for each section. The western section had four main entry points, while the eastern section (the reversible section) only had one. This advantages people who used the section for the entire time, as the per distance cost was the lowest; however, the time savings may be equivalent, depending on the location of the congestion.

Approximately 895,000 trips were taken during the afternoon hours of operation (2pm $7 \mathrm{pm}$ ) (Minnesota Department of Transportation 2005), which indicates less use in the afternoon despite a longer period of operation. Of people who exited the MnPASS lane at I-494, 74 percent entered the reversible section in Minneapolis. Of people who entered the system leaving Minneapolis (thereby using the reversible section), roughly 40 percent just used the reversible section, while nearly 40 percent drove in the lane nearly the entire way and exited at Ridgedale or I-494.

\section{Regression Analysis}

The initial description of the area served as a launching point for more detailed analysis. The initial analysis yielded suspicions of heteroskedasticity. The White Test confirmed this characteristic, thereby making the usual tests of significance inconsistent and corrective actions necessary (White 1980; Long and Ervin 1998; Pryce 2002). MacKinnon and White recognized this challenge and, building on the work of Hinkley (1977) and Efron (1982), devised a covariance matrix estimator, HC3. MacKinnon and White eventually concluded the HC3 is wise to employ even in the absence of heteroskedasticity (1985). Programming code for HC3 was imported into SPSS and used for the analysis (Hayes 2005).

Multiple approaches were employed in an attempt to address the equity questions; however, in the interest of brevity, most of the preliminary work has been omitted and/or condensed. Eventually, after various adjustments to the location and income variables were made and adjustments in aggregation levels made, four lane usage metrics were 
developed: (1) sum of tolls, (2) trip count, (3) average toll, and (4) total distance traveled on MnPASS. To provide additional insight, demand elasticities were estimated as well.

\subsection{Variables}

An assortment of variables were experimented with in an attempt to better understand the relationship of distance from downtown Minneapolis and the income levels. The variables included in the analysis were:

- tripcount - the number of trips made by each transponder

- tollsum - sum of the tolls paid by each transponder

- avgtoll - the average toll paid by transponder (tollsum/tripcount)

- totewdist - total eastbound and westbound distance traveled in the MnPASS lanes, measured in kilometers

- inc10k - median household income for zip code, assigned to the transponder and multiplied by 10,000 for scale

- d_mpls10k - distance from zip code centroid to I-394 terminus in downtown Minneapolis, measured in meters and multiplied by 10,000 for scale

- OwnMonth - number of months of transponder lease

- TrpsperMonth - trips per month (tripcount/month)

Every $\mathrm{HC} 3$ regression related to equity was run. OLS regressions were run as to confirm the findings; as anticipated the coefficients for the OLS and HC3 regressions were the same, but their standard errors differed. Correlations were calculated for variables.

\subsection{Correlations}

As shown in Table 4, the correlations in bold were found to be significant at the $\mathrm{p}<0.05$ level. Pearson correlations values between 0.5 and -0.5 were considered to be weakly correlated. Correlation values greater than 0.5 , or less than -0.5 , were considered to be strongly correlated. This analysis acknowledged the weak correlations, however; using weakly correlated variables as independent variables in the same regression. Regressions run using strongly correlated variables were removed from the model. The strongly correlated variables are included below.

- Trip count and sum of the tolls were strongly and positively correlated (0.85).

- Trip count and total distance traveled on MnPASS were strongly and positively correlated (0.52).

- Trip count and transponders per month were strongly and positively correlated (0.63).

- Sum of tolls and total distance traveled were strongly and positively correlated (0.52).

- Sum of tolls and transponders per month were strongly and positively correlated (0.55).

\subsection{Sum of Tolls}

Table 5 explains the sum of the tolls accrued per transponder in two models. Both models include median household income, distance to Minneapolis, and the months of transponder ownership, but only the first one includes trip count. 
Holding the included variables constant, the following relationships resulted from the regression:

- As median household income increased, so did the sum of the tolls in both models.

- As trip count increased, so did the sum of the tolls.

- As distance from Minneapolis increased, so did the sum of the tolls in both models.

- As months of transponder ownership increased, the first model controlling for trip count explains that the sum of tolls decreased, while the second model excluding trip count explains that the sum of tolls increased.

\subsection{Trip Count}

Table 6 explains the trip count per transponder in two models. Both models include median household income, distance to Minneapolis, and the months of transponder ownership, but only the first one includes sum of tolls.

Holding the included variables constant, the following relationships resulted from the regression:

- As median household income increased, the trip count decreased in the first model and was not significant in the second.

- As sum of tolls increased, so did the trip count.

- As distance from Minneapolis increased, so did the trip count in the first model and was not significant in the second.

- As months of transponder ownership increased, so did trip count in both models.

\subsection{Average Toll}

Table 7 explains the average toll per transponder in two models. Both models include median household income, distance to Minneapolis, and the months of transponder ownership, but only the first one includes trip count.

Holding the included variables constant, the following relationships resulted from the regression:

- As median household income increased, so did the average toll in both models.

- As trip count increased, so did the average toll.

- As distance from Minneapolis increased, so did the average toll in both models.

- As months of transponder ownership increased, the average toll decreased in both models.

\subsection{Total Distance Traveled on MnPASS}

Table 8 explains the total distance traveled on MnPASS per transponder in two models. Both models include median household income, distance to Minneapolis, and the months of transponder ownership, but only the first one includes trip count. 
Holding the included variables constant, the following relationships resulted from the regression:

- As median household income increased, so did the total distance traveled on MnPASS in both models.

- As trip count increased, so did the total distance traveled on MnPASS.

- As distance from Minneapolis increased, so did total distance traveled on MnPASS in both models.

- As months of transponder ownership increased, so did total distance traveled on MnPASS in both models.

\subsection{Elasticity}

Figure 2 graphs the number of trips taken at each toll price. When the toll price was $\$ 0.25$, nearly 650,000 trips were made on the system. The fewest number of trips were taken (341 trips) when the price was $\$ 7.75$. Interestingly, when the toll price was $\$ 8.00$ (the maximum price, intended to "price off" any additional users), 3,617 trips were taken. While tempting to read into this anomaly, it is important to remember that each toll price was not offered for the same amount of time and the pricing algorithm forbids the price from rising above the $\$ 8.00$ mark, i.e. drivers willing to pay more than $\$ 8.00$ were unable to do so and therefore pooled at that mark.

A natural log function represents the trend; as the price rose, the demand for the lane decreased. More precisely, the demand was inelastic when the price was high, with a value of 297.82. When the price was low, the demand was elastic, with a value of 0.34 . Drivers who had a very high value of time, paid whatever price was required as it was less than the cost of being late. Drivers with lower values of time were willing to be delayed even when the price rose only slightly. When the price increased from $\$ 0.25$ to $\$ 0.50,220,000$ drivers were "priced off" the lane. This elasticity does not account for changes in travel time on the general purpose (untolled) lanes, which tends to track with toll level.

\section{Discussion}

\subsection{Separating Income and Distance}

As the results demonstrated, distance from Minneapolis and median household income were both significant factors in predicting all four measures of use: sum of tolls paid, trip count, average toll, distance traveled on the MnPASS lanes. And while a significant correlation does exist between the distance from Minneapolis and median household income, the correlation is weak (0.37) and the results hold merit.

As the median household income increased for within the defined corridor, the following occurred:

- the sum of tolls grew larger,

- a larger average toll was paid,

- the total traveled distances on the MnPASS lanes increased, and

As distance from Minneapolis increased for within the defined corridor, 
- the sum of tolls grew larger,

- a larger average toll was paid,

- the total traveled distances on the MnPASS lanes increased, and

In both cases, the effect on number of trips was insignificant.

In practical terms, the wealthier residents paid larger average tolls, paid more in total tolls, and traveled a greater total distance on the MnPASS lanes than those with relatively lower incomes. Those living farther away from Minneapolis also paid larger average tolls, paid more in total tolls, and traveled a greater total distance on the MnPASS lanes than those who lived closer. Combining these variables, those that lived farther away and were wealthier, paid larger average tolls, paid more in total tolls, and traveled greater total distances. Those that lived closer to the City and made less money, paid lower average tolls, paid less in total tolls, and traveled shorter distances.

Of additional note was the finding that the longer a transponder was owned, the smaller the predicted average toll was. This suggested that a learning process took place during the lease period. However, free toll credits were used as an incentive to increase participation in the program and these toll credits expired three months after the lanes opened in August 2005 (Munnich 2007). Arranging the program in such a fashion may have encouraged people to use the lane at higher toll rates in an effort to use the credits before they expired.

\subsection{Other Equity Considerations}

While this paper expanded the range of measures to consider when addressing equity concerns it did not address at least five main additional benefits claimed for HOT lanes.

1. Vehicles shift from the general purpose lanes to the HOT lane, thereby reducing volumes and congestion within the general purpose lanes. This assumes that the number of travelers, induced to travel during the peak time because of the shorter travel times, are less than the number of vehicles that have shifted out of the general purpose lanes during the peak period and into the MnPASS lane.

2. Preservation of transit service within the corridor may ameliorate equity problems by providing a high quality transit alternative.

3. Even if transponders are not used, the lessee may still receive a benefit because the transponder acts as a sort of travel time insurance. It may not be used often, but, just like automobile insurance, it is there when needed.

4. The travel time reliability of both the general purpose lanes and the HOT lanes were not taken into account. As noted by Tilahun and Levinson (2006), travel time reliability to users is an important component of any transportation system and directing energy toward improving the reliability adds value. As applied to HOT lanes, if by converting an HOV lane to a HOT lane, the reliability of the entire system was improved, then one could make the case that the system's equity had improved as well.

5. When social benefits are paid for by those that choose to drive, the situational equity can be improved. For example, in the London Congestion Charge studies have found a reduction in harmful pollutants, decreases in greenhouse gas 
production, improved travel time for buses, and a decreased number of crashes (Transport for London 2005). If the lanes impact the corridor negatively, the cost of driving would have to be higher to compensate.

In terms of improving equity within the system, FAIR lanes/networks which provide toll and transit fare credits or refunds to low income users have been suggested (DeCorlaSouza 2004). Along similar lines another study investigated how a system in which the delayer pays for the congestion caused might shift the balance of equity. The study demonstrated that congestion pricing schemes, which compensate the delayed, can improve equity within a transportation network (Levinson and Rafferty 2004).

\subsection{Data and Methodological Short-comings}

There are three data short-comings that should be acknowledged that stem largely from the confidentiality of individuals' information. The individual characteristics of each MnPASS lessee were unable to be obtained resulting in the following:

1. The distance measurements taken to calculate the distance variables were measured from the centroid of the zip code, not an individual street address.

2. The median household income per zip code is applied to all individuals within the area and does not take into account variation as accurately as would be preferred. Access to information by census block group would have been brought finer variations into focus.

3. Since only the MnPASS portion of trips are tracked knowledge of which entry and exit gantries were known, however, the exact origins and destinations remained unknown. For example, if an individual used the MnPASS lane eastbound during the reversible section only, there is no way to be certain if driving in the section from I-494 was a reasonable option or whether they entered I-394 at MN-100. Assumptions based on zip codes and likely routes could be made, but are left to another study.

\section{Conclusion}

Equity issues stand as a critical hurdle in the implementation of road pricing projects. As with some public policy issues in the United States, visceral reactions often substitute for facts based on unbiased research. This paper increases the understanding of the I-394 MnPASS lanes through both the descriptive findings and through the results of the model.

This analysis provides conflicting evidence for the hypothesis that the I-394 MnPASS lanes are "Lexus Lanes." As income increases the model predicts that owners will spend a larger sum on tolls, pay a higher average toll, and travel longer total distances on the MnPASS lanes, though income's effect on number of trips was statistically insignificant. Yes, the lanes are "Lexus Lanes" in the sense that increased income predicts increases in three of the four use metrics used to measure direct benefit. However, there is more to be considered; distance from Minneapolis plays an important role as well.

The model finds that as the distance from Minneapolis increases, for those within the travelshed, the total sum of tolls, the average toll paid, and the total distance traveled on 
the MnPASS lane increase as well. As with income, increased distance from Minneapolis predicts three of the four use metrics.

Returning to the "Lexus Lane" question, the analysis demonstrates that individuals with higher incomes receive more direct benefits from the lane than those with lower incomes. However, that is not to say that lower income drivers receive no benefits. In addition to having fewer cars in the general purpose lanes as some drivers switch to the HOT lane, they may themselves use the lane on occasion, and thus gain a travel time insurance benefit from the lane's presence. 


\section{References}

Brownstone, D., A. Ghosh, et al. (2002). Drivers' Willingness-to-Pay to Reduce Travel Time: Evidence from the San Diego I-15 Congestion Pricing Project. San Diego Association of Governments. San Diego.

Burris, M. and R. Hannay (2003). Equity Analysis of the Houston QuickRide Project. Transportation Research Board Annual Meeting, Washington D.C., National Research Council.

Cambridge Systematics (2002). Twin Cities HOV, Volume 1 Final Repot. Minnesota Department of Transportation. St. Paul.

Clark, C. (1951). "Urban Population Densities." Journal of the Royal Statistical Society 114: 490-496.

DeCorla-Souza, P. (2004). "An Evaluation of "High Occupancy Toll" and "Fast and Intertwined Regulat" Networks." Transportation Research Board 2004.

Efron, B. (1982). The Jackknife, the Bootstrap and Other Sampling Plans. Society for Industrial and Applied Mathematics. Philadelphia, PA.

Federal Highway Administration. (2007). "Highway Community Exchange."

Hayes, A. F. (2005). Statistical Methods for Communication Science, from the CD accompanying. Mahwah, NJ, Lawrence Erlbaum Associates.

Hinkley, D. V. (1977). "Jackknifing in Unbalanced Situations." Technometrics 19: 285-292.

Jenks, G. (1967). "The Data Model Concept in Statistical Mapping." International Yearbook of Cartography 7: 186-190.

Levinson, D. and P. Rafferty (2004). "Delayer Pays Principle: Examining Congestion Pricing with Compensation." International Journal of Transport Economics 31(3): 295-311.

Long, J. S. and L. H. Ervin (1998). Correcting for Heteroscedasticity with Heteroscedasticity Consistent Standard Errors in the Linear Regression Model: Small Sample Considerations. Indiana University. Bloomington.

MacKinnon, J. G. and H. White (1985). "Some Heteroskedasticity-Consistent Covariance Matrix Estimators with Improved Finite Sample Properties." Journal of Econometrics 29: 305-325.

Minnesota Department of Transportation. (2005). "About MnPASS: The Expressway to Work." from http://www.mnpass.org/.

Minnesota Department of Transportation (2005). MnDOT Progresses on I-394 Express Lane.

Moxley, R. S. (2000). Highway Robbery - Toll Roads. OCWeekly. Orange County, CA. January 12, 2000.

Munnich, L. (2007). Comments on MnPASS Marketing Program. T. Patterson. Minneapolis.

Pryce, G. (2002). Heteroscedasticity: Testing and Correcting in SPSS. University of Glasgow.

Regan, E. (2004). Some Like it HOT. American City and County.

http://www.americancityandcounty.com/mag/government_hot/. 
Small, K., C. Winston, et al. (1989). Road Work: A New Highway Pricing \& Investment Policy. Washington D.C., Brookings Institution.

Sullivan, E. (1998). Evaluating the Impacts of the SR 91 Variable-Toll Express Lane Facility Final Report. Cal Poly State University.

Sullivan, E. (2000). Continuation Study to Evaluate the Impacts of the SR 91 Value-Priced Express Lanes Final Report. Cal Poly State University.

Supernak, J. (1998). I-15 Congestion Pricing Project: Task 3.2.3, Phase I Attitudinal Panel Survey. San Diego Association of Governments. San Diego.

Supernak, J. (1998). I-15 Congestion Pricing Project: Task 3.3.7, Phase I Acceptance of the Project and the Pricing Concept. San Diego Association of Governments. San Diego.

Supernak, J. (2000). I-15 Congestion Pricing Project Monitoring and Evaluating Services: Task 8, Phase II Year Two Attitudinal Panel Survey. San Diego Association of Governments. San Diego.

Tilahun, N. and D. Levinson (2006). A Moment of Time: Reliability in Route Choice using Stated Preference 11th International Association of Travel Behaviour Research Conference Kyoto, Japan.

Transport for London (2005). Congestion Charging: Third Annual Monitoring Report. Mayor of London. London.

Vickrey, W. (1969). "Congestion Theory and Transport Investment." American Economic Review 59: 251260.

White, H. (1980). "A Heteroskedasticity-Consisten Covariance Matrix Estimator and a Direct Test for Heteroskedasticity." Econometrica 48(4): 817-838.

Wilbur Smith and Associates (1996). I-15 Congestion Pricing Project: Task 3-A, Baseline Market Survey. San Diego Association of Governments. 


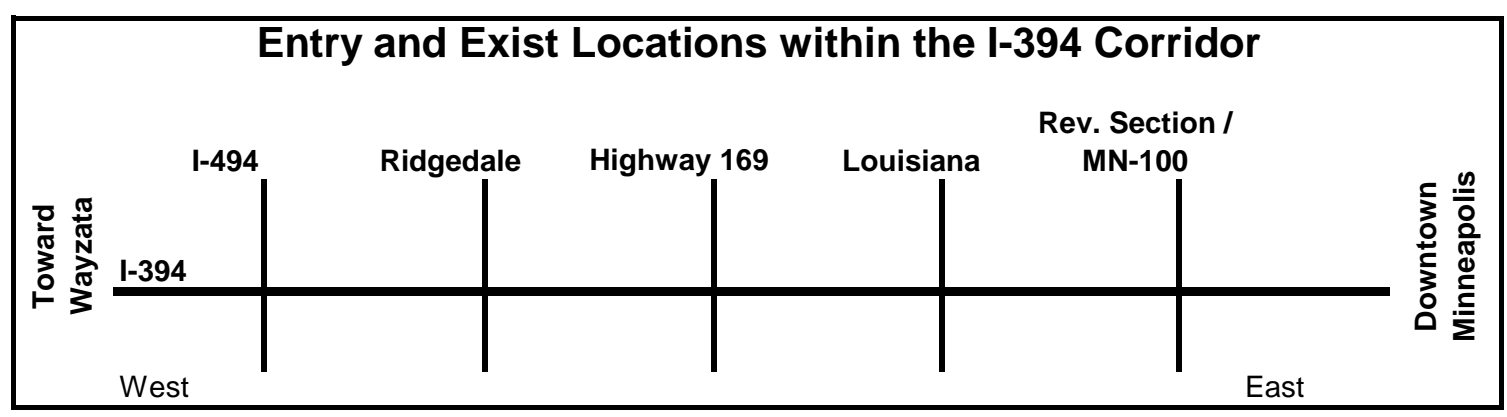

Figure 1: Major entry and exit points within the I-394 corridor for MnPASS users. All entries and exits are coded to these locations, although intermediary exits do exist.

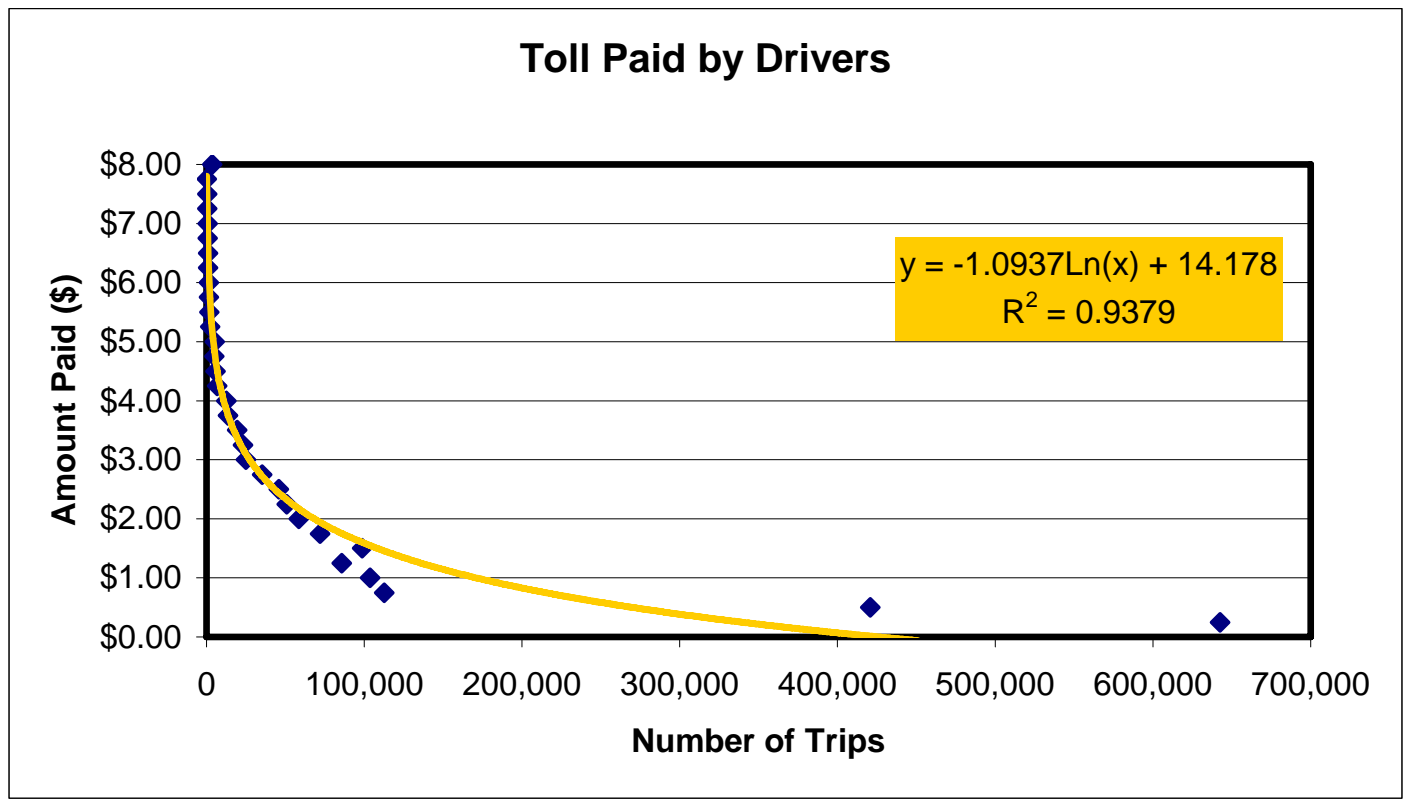

Figure 2: Price elasticity of tolls paid by drivers 
What do you think of allowing single drivers to use the carpool lanes by paying a toll?

\begin{tabular}{|c|c|c|c|}
\hline \multicolumn{4}{|c|}{ Respondents* } \\
\hline & Good Idea & Bad Idea & No Opinion \\
\hline All Respondents & $61 \%$ & $26 \%$ & $13 \%$ \\
\hline \multicolumn{4}{|c|}{ Respondents by Income } \\
\hline & Good Idea & Bad Idea & No Opinion \\
\hline Less than $\$ 50 \mathrm{~K}$ & $65 \%$ & $20 \%$ & $15 \%$ \\
\hline More than $\$ 50 \mathrm{~K}$ & $61 \%$ & $27 \%$ & $12 \%$ \\
\hline \multicolumn{4}{|c|}{ Respondents by Gender } \\
\hline & Good Idea & Bad Idea & No Opinion \\
\hline Male & $60 \%$ & $28 \%$ & $12 \%$ \\
\hline Female & $64 \%$ & $23 \%$ & $14 \%$ \\
\hline \multicolumn{4}{|c|}{ Respondents by Education Level } \\
\hline & Good Idea & Bad Idea & No Opinion \\
\hline High School or Less & $60 \%$ & $25 \%$ & $17 \%$ \\
\hline College/Trade/Vocational & $62 \%$ & $24 \%$ & $15 \%$ \\
\hline BA/BS Degree & $62 \%$ & $26 \%$ & $12 \%$ \\
\hline Graduate Work & $61 \%$ & $26 \%$ & $11 \%$ \\
\hline
\end{tabular}

*Respondents are randomly selected residents of I-394 and I-35W corridors.

Source: Humphrey Institute I-394 Survey, conducted from May and June 2006, N=944, Wave 3

Table 1: Perception of Allowing Single-occupant Vehicles to Use Carpool Lane by Paying a Fee 


\begin{tabular}{|c|c|c|c|c|c|c|c|}
\hline & & \multicolumn{5}{|c|}{ Exit Plaza } & \multirow[b]{2}{*}{ Total } \\
\hline & & $\mathrm{I}-494$ & Ridgedale & Hwy 169 & Louisiana & Minneapolis & \\
\hline \multirow{6}{*}{$\begin{array}{l}\text { Entry } \\
\text { Plaza }\end{array}$} & I-494 & 6684 & 5822 & 22772 & 11136 & 194452 & 240866 \\
\hline & Ridgedale & & 4781 & 11223 & 9039 & 142328 & 167371 \\
\hline & Hwy 169 & & & 5233 & 4574 & 69963 & 79770 \\
\hline & Louisiana & & & & 5402 & 83482 & 88884 \\
\hline & Rev. Section & & & & & 416145 & 416145 \\
\hline & Total & 6684 & 10603 & 39228 & 30151 & 906370 & 993036 \\
\hline
\end{tabular}

Table 2: Crosstabulations of entry and exit points during the eastbound commute toward Minneapolis

\begin{tabular}{|c|c|c|c|c|c|c|c|}
\hline & & \multicolumn{5}{|c|}{ Exit Plaza } & \multirow[b]{2}{*}{ Total } \\
\hline & & Rev. Section & Louisiana & Hwy 169 & Ridgedale & $\mathrm{I}-494$ & \\
\hline \multirow{6}{*}{$\begin{array}{l}\text { Entry } \\
\text { Plaza }\end{array}$} & Minneapolis & 325976 & 88950 & 72062 & 142234 & 155598 & 784820 \\
\hline & Louisiana & & 8228 & 7315 & 14128 & 14890 & 44625 \\
\hline & Hwy 169 & & & 6218 & 13095 & 19533 & 38846 \\
\hline & Ridgedale & & & & 7045 & 11843 & 18888 \\
\hline & I-494 & & & & & 8045 & 8045 \\
\hline & & 326040 & 97178 & 85595 & 176502 & 209909 & 895224 \\
\hline
\end{tabular}

Table 3: Crosstabulations of entry and exit points during the westbound commute out of Minneapolis 


\begin{tabular}{|c|c|c|c|c|c|c|c|c|}
\hline \multicolumn{9}{|c|}{ Pearson Correlations } \\
\hline & & tripcount $t$ & Isum & avgtoll & totewdist i & רc10K c & d_mpls10K C & OwnMonths \\
\hline tripcount & $\begin{array}{l}\begin{array}{l}\text { Correlation } \\
\text { Sig. (2-tailed) }\end{array} \\
\end{array}$ & 1 & & & & & & \\
\hline tollsum & $\begin{array}{l}\text { Correlation } \\
\text { Sig. (2-tailed) }\end{array}$ & $\begin{array}{l}\mathbf{0 . 8 4 9} \\
0.000 \\
\end{array}$ & 1 & & & & & \\
\hline avgtoll & $\begin{array}{l}\text { Correlation } \\
\text { Sig. (2-tailed) }\end{array}$ & $\begin{array}{l}\mathbf{0 . 0 9 9} \\
0.000\end{array}$ & $\begin{array}{l}\mathbf{0 . 4 0 8} \\
0.000\end{array}$ & 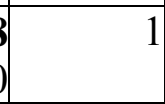 & & & & \\
\hline totewdist & $\begin{array}{l}\text { Correlation } \\
\text { Sig. (2-tailed) }\end{array}$ & $\begin{array}{l}\mathbf{0 . 5 1 7} \\
0.000 \\
\end{array}$ & $\begin{array}{l}\mathbf{0 . 5 2 0} \\
0.000 \\
\end{array}$ & $\begin{array}{l}\mathbf{0 . 0 9 6} \\
0.000 \\
\end{array}$ & 1 & & & \\
\hline inc10K & $\begin{array}{l}\text { Correlation } \\
\text { Sig. (2-tailed) }\end{array}$ & $\begin{array}{l}0.002 \\
0.866\end{array}$ & $\begin{array}{l}\mathbf{0 . 0 7 8} \\
0.000\end{array}$ & $\begin{array}{l}\mathbf{0 . 1 6 5} \\
0.000\end{array}$ & $\begin{array}{r}-0.260 \\
0.000\end{array}$ & 1 & & \\
\hline d_mpls10K & $\begin{array}{l}\text { Correlation } \\
\text { Sig. (2-tailed) }\end{array}$ & $\begin{array}{l}0.000 \\
0.998\end{array}$ & $\begin{array}{l}\mathbf{0 . 1 0 9} \\
0.000\end{array}$ & $\begin{array}{l}\mathbf{0 . 2 3 7} \\
0.000\end{array}$ & $\begin{array}{l}\mathbf{0 . 1 2 2} \\
0.000\end{array}$ & $\begin{array}{l}\mathbf{0 . 3 7 4} \\
0.000\end{array}$ & 1 & \\
\hline OwnMonths & \begin{tabular}{|l}
$\begin{array}{l}\text { Correlation } \\
\text { Sig. (2-tailed) }\end{array}$ \\
\end{tabular} & $\begin{array}{l}\mathbf{0 . 2 8 7} \\
0.000 \\
\end{array}$ & $\begin{array}{l}\mathbf{0 . 1 9 5} \\
0.000 \\
\end{array}$ & $\begin{array}{r}\mathbf{- 0 . 1 9 9} \\
0.000 \\
\end{array}$ & $\begin{array}{l}\mathbf{0 . 2 3 7} \\
0.000 \\
\end{array}$ & $\begin{array}{r}-0.003 \\
0.788 \\
\end{array}$ & $\begin{array}{l}\mathbf{0 . 0 4 1} \\
0.000 \\
\end{array}$ & 1 \\
\hline TrpsperMonth & $\begin{array}{l}\text { Correlation } \\
\text { Sig. (2-tailed) }\end{array}$ & $\begin{array}{l}\mathbf{0 . 6 3 3} \\
0.000 \\
\end{array}$ & $\begin{array}{l}\mathbf{0 . 5 5 3} \\
0.000\end{array}$ & $\begin{array}{l}\mathbf{0 . 1 2 4} \\
0.000\end{array}$ & $\begin{array}{l}\mathbf{0 . 2 6 0} \\
0.000\end{array}$ & $\begin{array}{l}0.006 \\
0.573\end{array}$ & $\begin{array}{r}\mathbf{- 0 . 0 3 1} \\
0.002 \\
\end{array}$ & $\begin{array}{r}\mathbf{- 0 . 1 2 8} \\
0.000 \\
\end{array}$ \\
\hline
\end{tabular}

Table 4: Pearson correlations of variables 


\begin{tabular}{|l|cccc|cccc|}
\hline & $\beta$ & $\mathrm{SE}(\mathrm{HC})$ & $\mathrm{t}$ & $\mathrm{p}$ & $\beta$ & $\mathrm{SE}(\mathrm{HC})$ & $\mathrm{t}$ & $\mathrm{p}$ \\
\cline { 2 - 9 } Constant & $\mathbf{0 . 7 0 6}$ & $\mathbf{0 . 0 3 2}$ & $\mathbf{2 2 . 2 3 4}$ & $\mathbf{0 . 0 0 0}$ & $\mathbf{0 . 7 1 6}$ & $\mathbf{0 . 0 3 2}$ & $\mathbf{2 2 . 4 1 1}$ & $\mathbf{0 . 0 0 0}$ \\
Median hh income *10k & $\mathbf{0 . 0 3 5}$ & $\mathbf{0 . 0 0 4}$ & $\mathbf{8 . 4 5 0}$ & $\mathbf{0 . 0 0 0}$ & $\mathbf{0 . 0 3 5}$ & $\mathbf{0 . 0 0 4}$ & $\mathbf{8 . 4 8 6}$ & $\mathbf{0 . 0 0 0}$ \\
Trip Count & $\mathbf{0 . 0 0 1}$ & $\mathbf{0 . 0 0 0}$ & $\mathbf{1 9 . 6 2 7 5}$ & $\mathbf{0 . 0 0 0}$ & & & & \\
Distance to Mpls * 10k & $\mathbf{0 . 1 6 1}$ & $\mathbf{0 . 0 0 8}$ & $\mathbf{2 1 . 2 1 0}$ & $\mathbf{0 . 0 0 0}$ & $\mathbf{0 . 1 5 9}$ & $\mathbf{0 . 0 0 8}$ & $\mathbf{2 0 . 5 8 1}$ & $\mathbf{0 . 0 0 0}$ \\
Mnths of transp ownership & $\mathbf{- 0 . 0 2 0}$ & $\mathbf{0 . 0 0 1}$ & $\mathbf{- 2 2 . 2 5 0}$ & $\mathbf{0 . 0 0 0}$ & $\mathbf{- 0 . 0 1 6}$ & $\mathbf{0 . 0 0 1}$ & $\mathbf{- 1 8 . 2 2 3}$ & $\mathbf{0 . 0 0 0}$ \\
\cline { 2 - 8 } & 0.74 & & & & 0.11 & & & \\
\hline
\end{tabular}

Table 5: Dependent Variable: sum of tolls per transponder

(terms significant at the $p<0.05$ level are indicated in bold)

\begin{tabular}{|l|cccc|cccc|}
\hline & $\beta$ & $\mathrm{SE}(\mathrm{HC})$ & $\mathrm{t}$ & $\mathrm{p}$ & $\beta$ & $\mathrm{SE}(\mathrm{HC})$ & $\mathrm{t}$ & $\mathrm{p}$ \\
\cline { 2 - 9 } Constant & $\mathbf{5 8 . 1 2 2}$ & $\mathbf{5 . 5 3 9}$ & $\mathbf{1 0 . 4 9 3}$ & $\mathbf{0 . 0 0 0}$ & 18.961 & 9.751 & 1.945 & 0.052 \\
Median hh income *10k & $\mathbf{- 4 . 1 4 7}$ & $\mathbf{0 . 7 3 9}$ & $\mathbf{- 5 . 6 0 8}$ & $\mathbf{0 . 0 0 0}$ & 1.063 & 1.350 & 0.788 & 0.431 \\
Sum of tolls & $\mathbf{0 . 6 6 3}$ & $\mathbf{0 . 0 0 8}$ & $\mathbf{8 7 . 6 3 3 3}$ & $\mathbf{0 . 0 0 0}$ & & & & \\
Distance to Mpls * 10k & $\mathbf{- 2 0 . 1 7 1}$ & $\mathbf{1 . 3 2 2}$ & $\mathbf{- 1 5 . 2 5 7}$ & $\mathbf{0 . 0 0 0}$ & -3.507 & 2.471 & -1.419 & 0.156 \\
Mnths of transp ownership & $\mathbf{3 . 0 9 0}$ & $\mathbf{0 . 0 9 1}$ & $\mathbf{3 3 . 9 5 2}$ & $\mathbf{0 . 0 0 0}$ & $\mathbf{6 . 9 7 9}$ & $\mathbf{0 . 1 7 0}$ & $\mathbf{4 1 . 1 6 2}$ & $\mathbf{0 . 0 0 0}$ \\
\cline { 2 - 8 } & 0.75 & & & & 0.08 & & & \\
\hline
\end{tabular}

Table 6: Dependent Variable: trip count per transponder

\begin{tabular}{|l|cccc|cccc|}
\hline & $\beta$ & $\mathrm{SE}(\mathrm{HC})$ & $\mathrm{t}$ & $\mathrm{p}$ & $\beta$ & $\mathrm{SE}(\mathrm{HC})$ & $\mathrm{t}$ & $\mathrm{p}$ \\
\cline { 2 - 9 } Constant & $\mathbf{0 . 7 0 6}$ & $\mathbf{0 . 0 3 2}$ & $\mathbf{2 2 . 2 3 4}$ & $\mathbf{0 . 0 0 0}$ & $\mathbf{0 . 7 1 6}$ & $\mathbf{0 . 0 3 2}$ & $\mathbf{2 2 . 4 1 1}$ & $\mathbf{0 . 0 0 0}$ \\
Median hh income *10k & $\mathbf{0 . 0 3 5}$ & $\mathbf{0 . 0 0 4}$ & $\mathbf{8 . 4 5 0}$ & $\mathbf{0 . 0 0 0}$ & $\mathbf{0 . 0 3 5}$ & $\mathbf{0 . 0 0 4}$ & $\mathbf{8 . 4 8 6}$ & $\mathbf{0 . 0 0 0}$ \\
Trip Count & $\mathbf{0 . 0 0 1}$ & $\mathbf{0 . 0 0 0}$ & $\mathbf{1 9 . 6 2 7 5}$ & $\mathbf{0 . 0 0 0}$ & & & & \\
Distance to Mpls * 10k & $\mathbf{0 . 1 6 1}$ & $\mathbf{0 . 0 0 8}$ & $\mathbf{2 1 . 2 1 0}$ & $\mathbf{0 . 0 0 0}$ & $\mathbf{0 . 1 5 9}$ & $\mathbf{0 . 0 0 8}$ & $\mathbf{2 0 . 5 8 1}$ & $\mathbf{0 . 0 0 0}$ \\
Mnths of transp ownership & $\mathbf{- 0 . 0 2 0}$ & $\mathbf{0 . 0 0 1}$ & $\mathbf{- 2 2 . 2 5 0}$ & $\mathbf{0 . 0 0 0}$ & $\mathbf{- 0 . 0 1 6}$ & $\mathbf{0 . 0 0 1}$ & $\mathbf{- 1 8 . 2 2 3}$ & $\mathbf{0 . 0 0 0}$ \\
\cline { 2 - 8 } \multicolumn{1}{c|}{$\mathrm{R}^{2}$} & 0.74 & \multicolumn{1}{|c|}{} & & 0.11 & & & \\
\hline
\end{tabular}

Table 7: Dependent Variable: average toll per transponder

\begin{tabular}{|l|cccc|cccc|}
\hline & $\beta$ & $\mathrm{SE}(\mathrm{HC})$ & $\mathrm{t}$ & $\mathrm{p}$ & $\beta$ & $\mathrm{SE}(\mathrm{HC})$ & $\mathrm{t}$ & $\mathrm{p}$ \\
\cline { 2 - 9 } Constant & $-\mathbf{6 1 7 . 4 8 3}$ & $\mathbf{3 4 . 6 8 4}$ & $\mathbf{- 1 7 . 8 0 3}$ & $\mathbf{0 . 0 0 0}$ & $\mathbf{- 5 7 7 . 8 6 1}$ & $\mathbf{3 6 . 8 4 9}$ & $\mathbf{- 1 5 . 6 8 2}$ & $\mathbf{0 . 0 0 0}$ \\
Median hh income *10k & $\mathbf{3 1 . 2 4 1}$ & $\mathbf{4 . 6 0 9}$ & $\mathbf{6 . 7 7 9}$ & $\mathbf{0 . 0 0 0}$ & $\mathbf{3 3 . 4 6 3}$ & $\mathbf{5 . 1 0 1}$ & $\mathbf{6 . 5 6 0}$ & $\mathbf{0 . 0 0 0}$ \\
Trip Count & $\mathbf{2 . 0 9 0}$ & $\mathbf{0 . 0 9 2}$ & $\mathbf{2 2 . 6 9 7 2}$ & $\mathbf{0 . 0 0 0}$ & & & & \\
Distance to Mpls * 10k & $\mathbf{9 9 . 0 8 8}$ & $\mathbf{9 . 3 8 1}$ & $\mathbf{1 0 . 5 6 3}$ & $\mathbf{0 . 0 0 0}$ & $\mathbf{9 1 . 7 6 1}$ & $\mathbf{1 0 . 4 6 8}$ & $\mathbf{8 . 7 6 6}$ & $\mathbf{0 . 0 0 0}$ \\
Mnths of transp ownership & $\mathbf{9 . 5 3 6}$ & $\mathbf{0 . 5 1 4}$ & $\mathbf{1 8 . 5 6 3}$ & $\mathbf{0 . 0 0 0}$ & $\mathbf{2 4 . 1 1 9}$ & $\mathbf{0 . 7 7 7}$ & $\mathbf{3 1 . 0 4 9}$ & $\mathbf{0 . 0 0 0}$ \\
\cline { 2 - 8 } & 0.74 & & & & 0.07 & & & \\
\hline
\end{tabular}

Table 8: Dependent Variable: total distance traveled on MnPASS per transponder 


\section{Zip Codes and Water Bodies}

\section{May 2005 - July 2007}

Twin Cities Metropolitan Area, United States

\section{Legend}

\section{Zip Codes and Water Bodies}

$\square$ Zip Code

Water Body

\section{Roadway System}

MnPASS Corridor

Interstate

MN Highway

US Highway
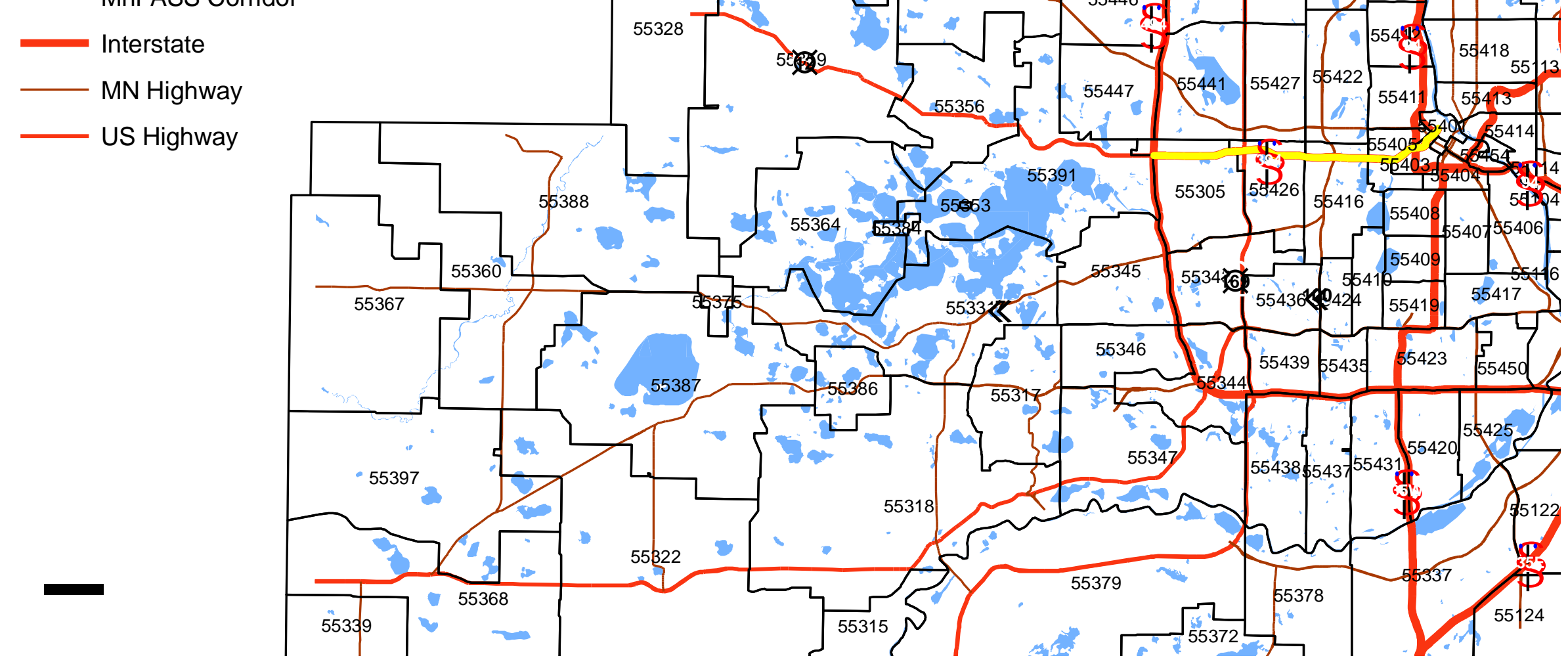

Data Source: Minnesota Department of Transportation Database

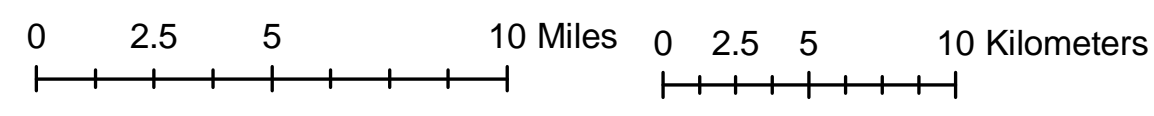

US Census 2000, Metro GIS

Tyler Patterson

University of Minnesota 


\section{Median Household Income by Zip Code}

May 2005 - July 2007

Twin Cities Metropolitan Area, United States

\section{Legend}

Median Household Income

$\$ 14,360-\$ 36,607$

$\$ 36,608$ - $\$ 50,616$

$\$ 50,617-\$ 62,347$

$\$ 62,348$ - $\$ 76,010$

$\$ 76,011$ - $\$ 95,372$

No data

\section{Roadway System}

Interstate MnPASS Corridor US Highway MN Highway

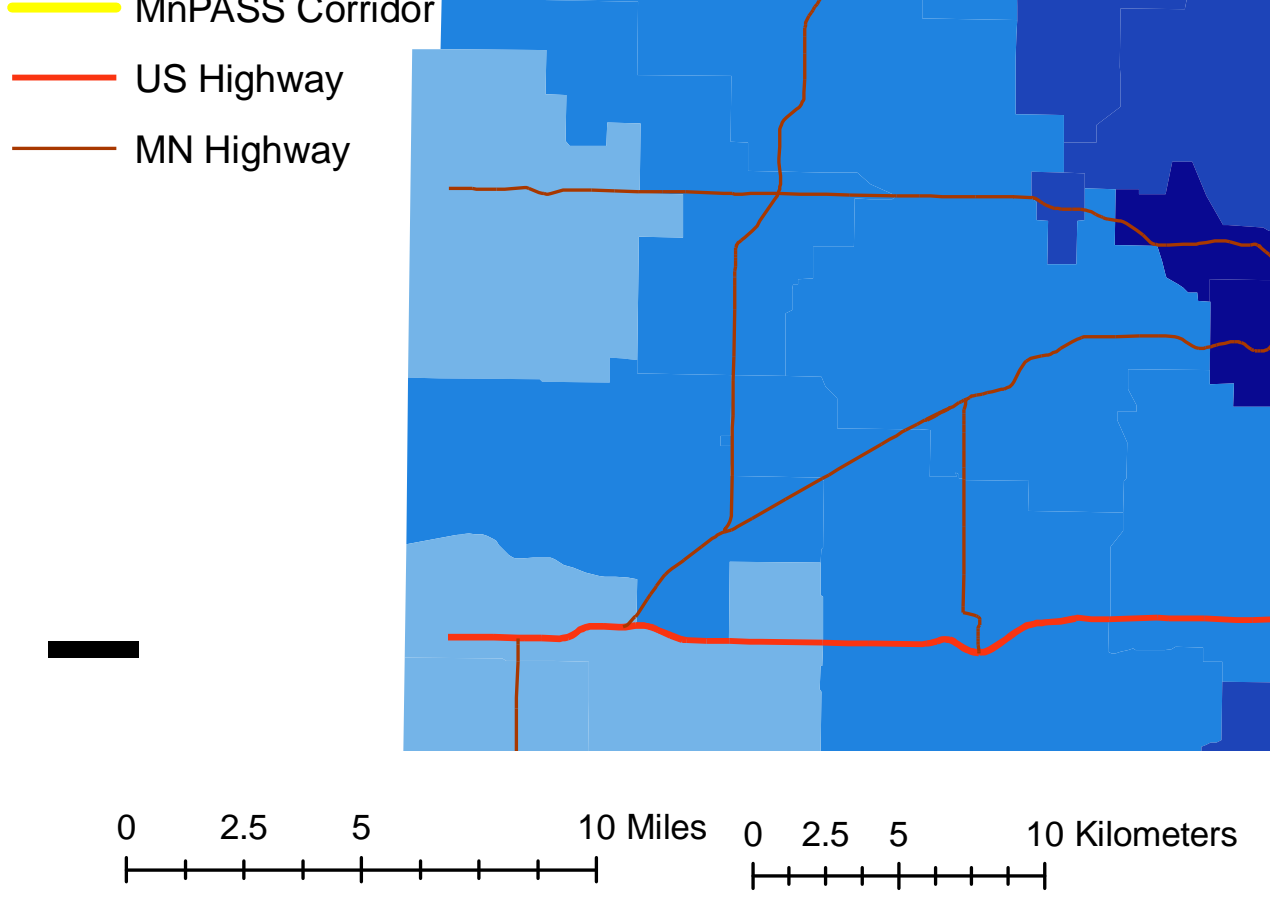

Data Source: Minnesota Department of Transportation Database US Census 2000, Metro GIS 


\section{Population Density by Zip Code}

May 2005 - July 2007

Twin Cities Metropolitan Area, United States

\section{Legend}

Population Density

\begin{tabular}{|l}
\hline Lowest \\
Low - Medium \\
Medium \\
Med - High \\
Highest \\
\hline No data
\end{tabular}

\section{Roadway System}

Interstate MnPASS Corridor US Highway MN Highway

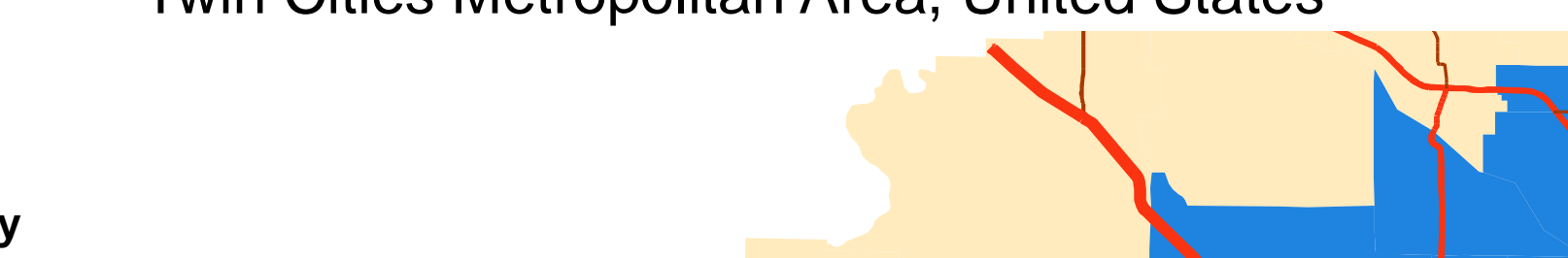

(n)




\section{Transponders per 1,000 Persons by Zip Code}

May 2005 - July 2007

Twin Cities Metropolitan Area, United States

\section{Legend}

Transponders per 1,000 Persons

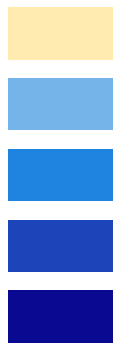

$0-6.6$

$6.6-25.7$

$25.7-51.0$

$51.0-93.7$

$93.7-1,318.2$

\section{Roadway System}

Interstate

MnPASS Corridor

— US Highway

— MN Highway

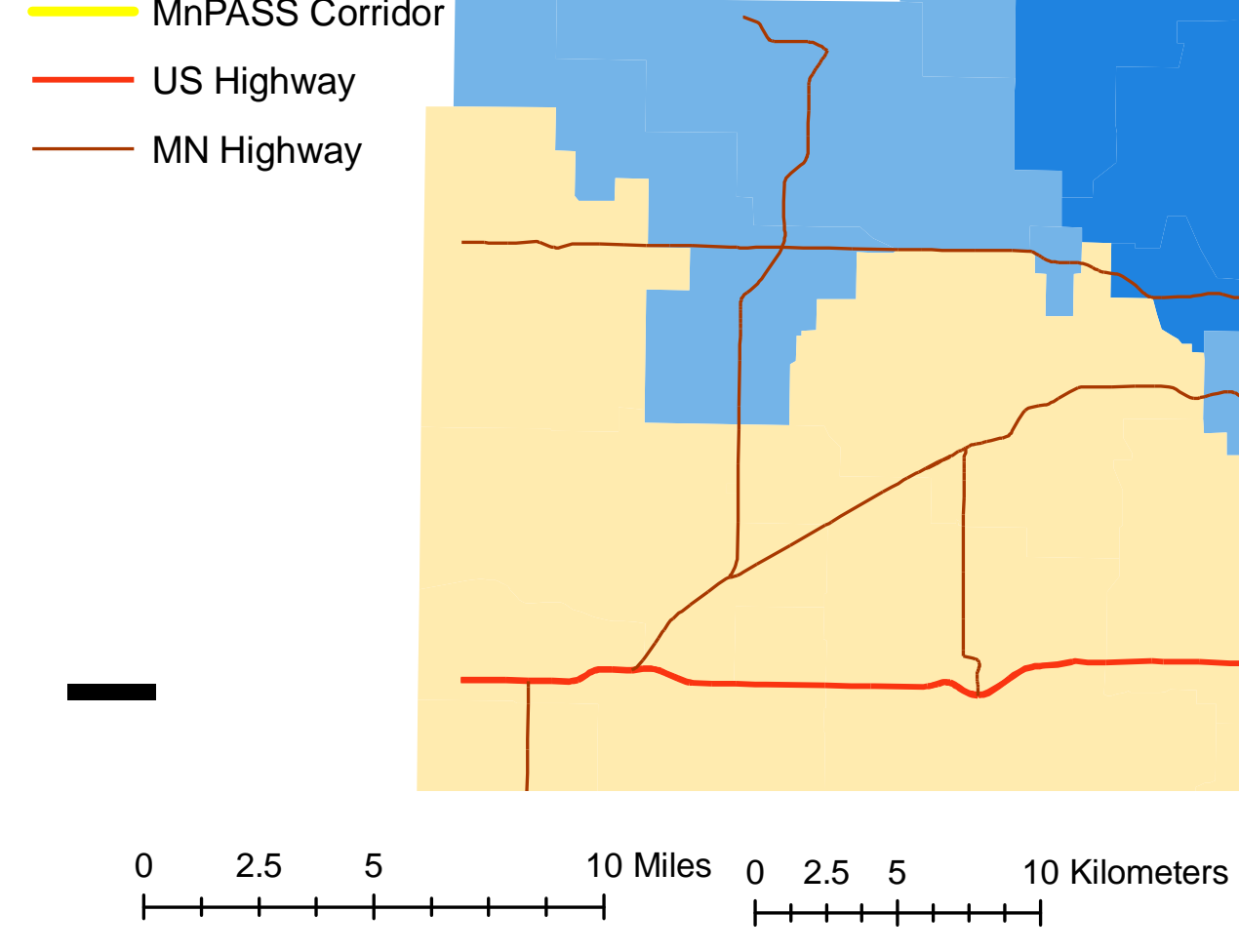

$\mathbb{q}^{2}$

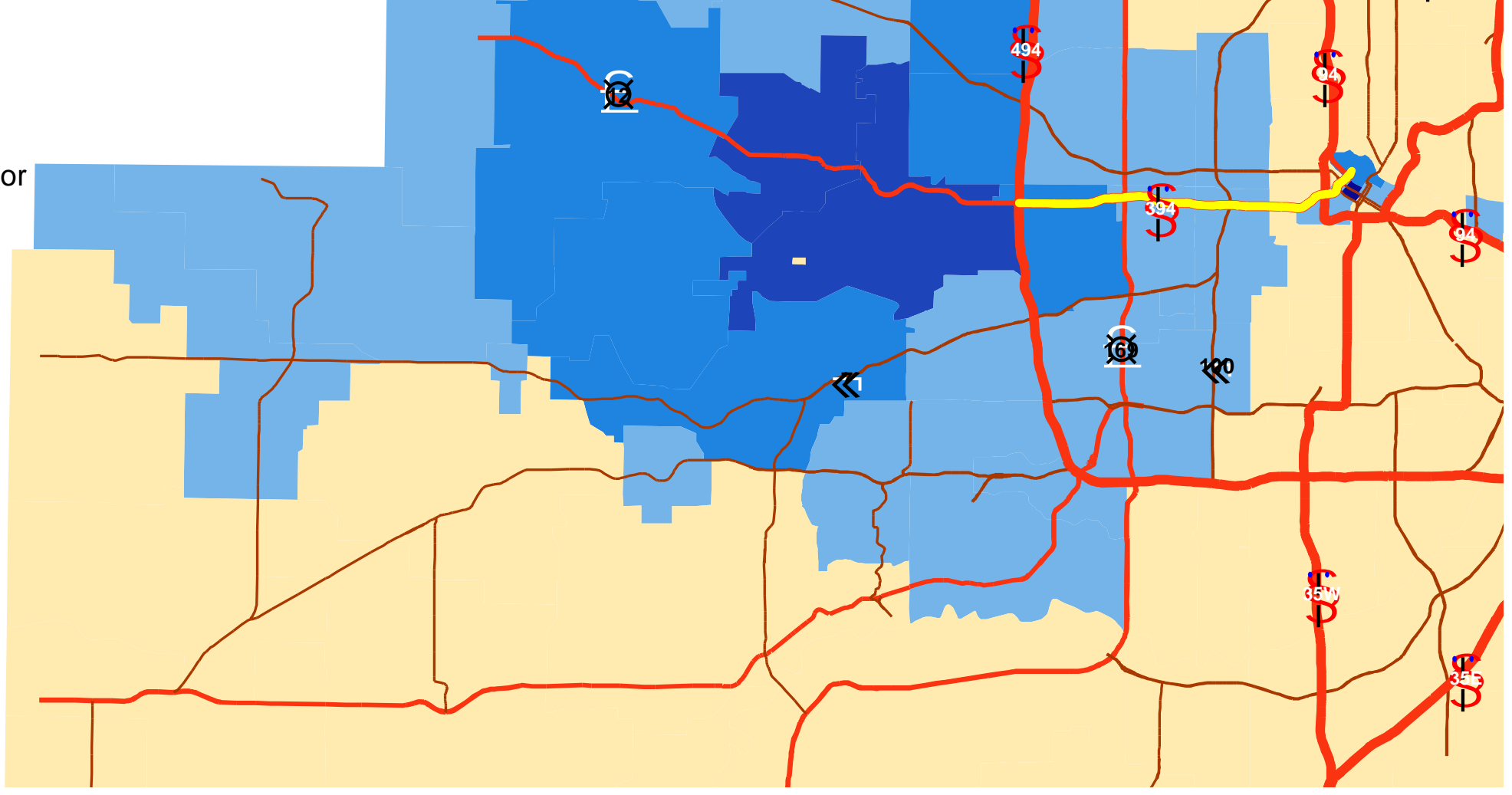

Data Source: Minnesota Department of Transportation Database US Census 2000, Metro GIS 


\section{MnPASS Trips by Zip Code}

May 2005 - July 2007

\section{Legend}

\section{Trip Count}

$0-6,388$

$6,389-21,721$

$21,722-53,677$

$53,678-97,890$

$97,891-195,585$

\section{Roadway System}

MnPASS Corridor

Interstate

MN Highway

— US Highway

\section{Twin Cities Metropolitan Area, United States}

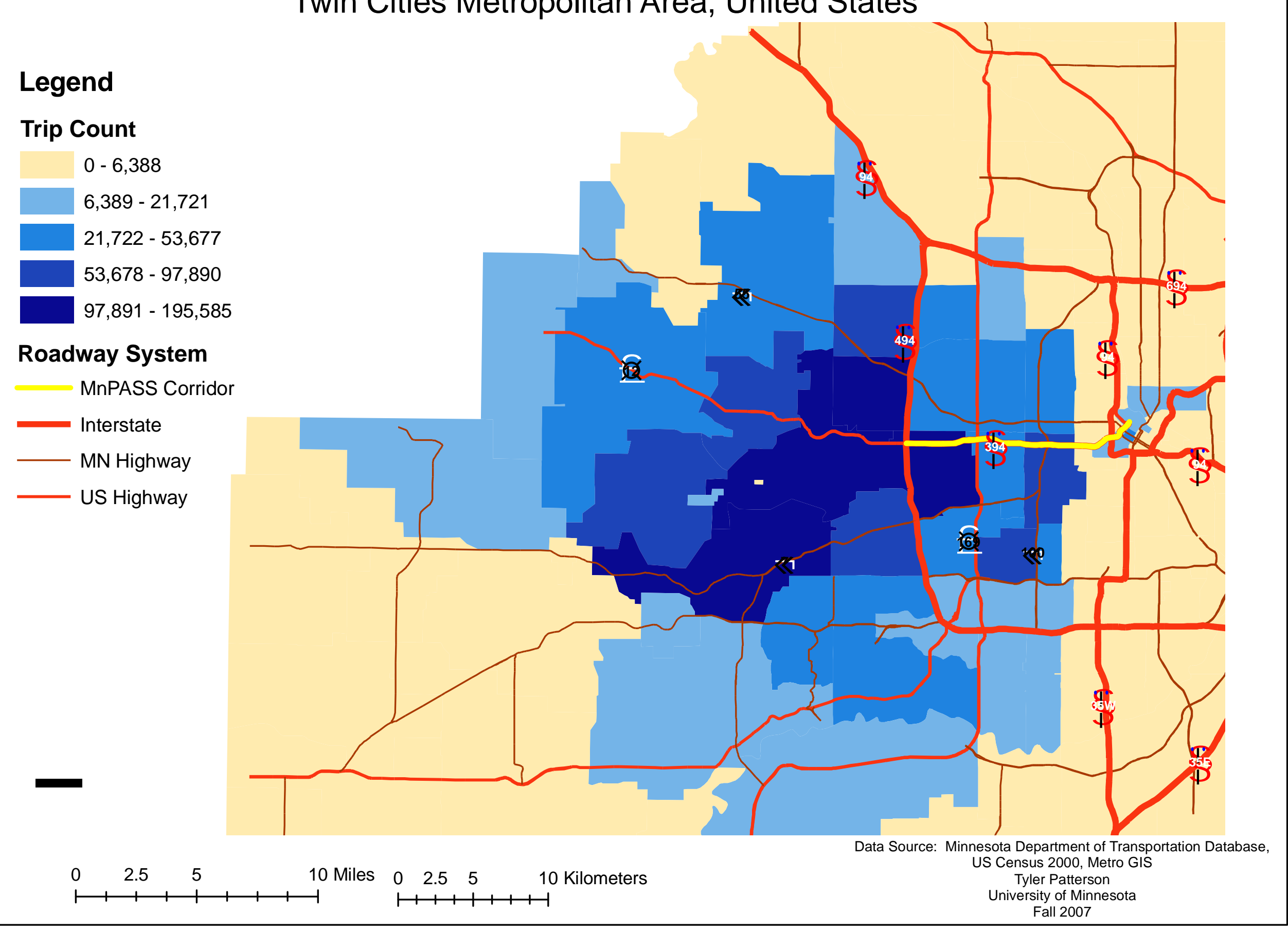




\section{Trip Density: Trips per Person by Zip Code}

\section{Legend}

Trip Density

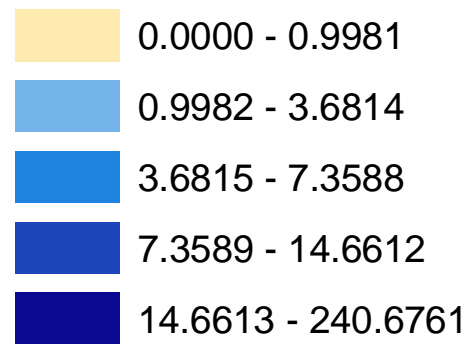
May 2005 - July 2007 Twin Cities Metropolitan Area, United States

\section{Roadway System}

MnPASS Corridor

Interstate

- MN Highway

— US Highway
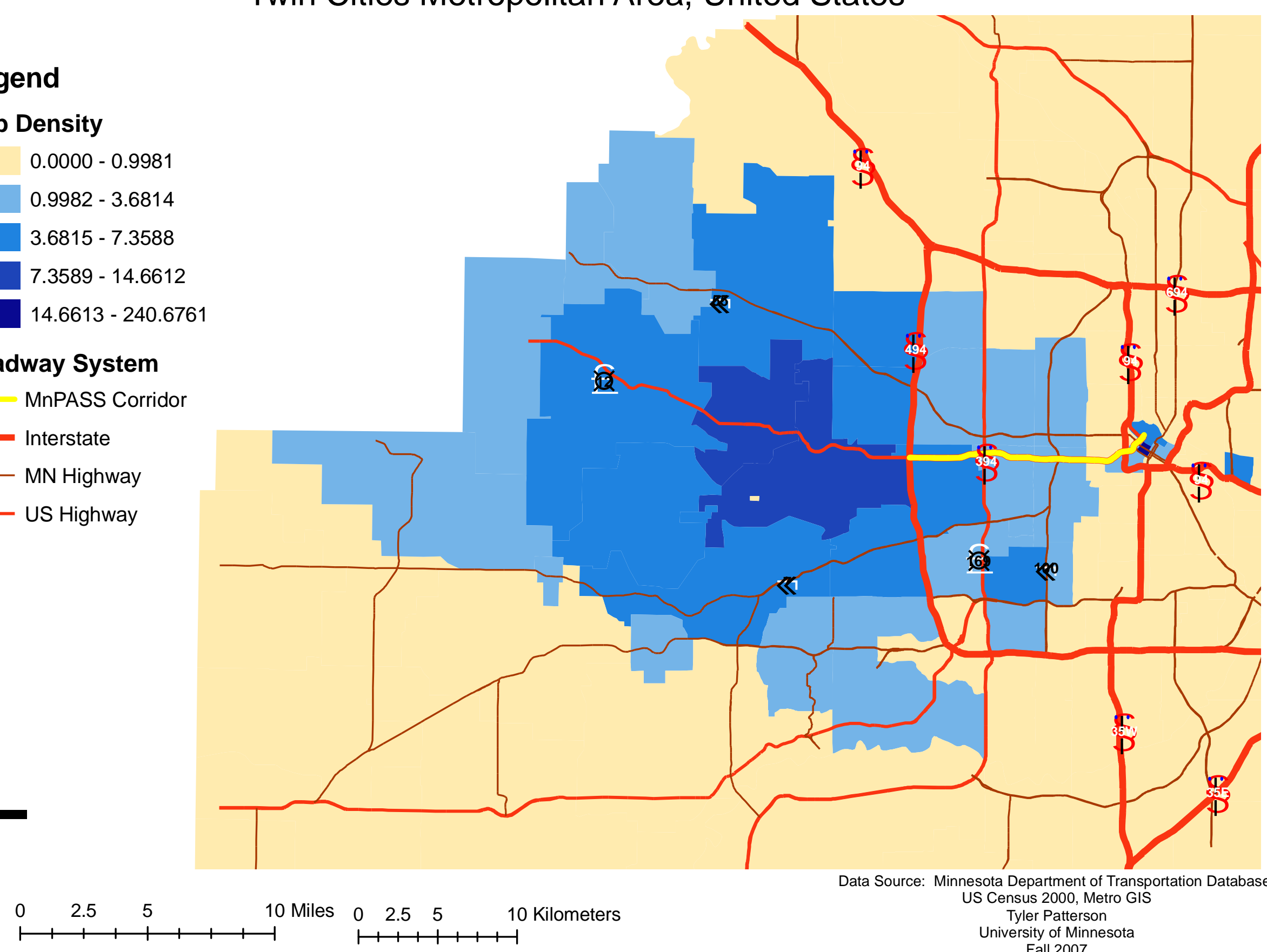

Data Source: Minnesota Department of Transportation Database, US Census 2000, Metro GIS Tyler Patterson
University of Minnesota Fall 2007 


\section{Zip Code Sample Selection}

May 2005 - July 2007

Twin Cities Metropolitan Area, United States

\section{Legend}

Zip Codes with $\mathbf{9 0 \%}$ of Trips

10,995 - 195,585

\section{Zip Codes with 95\% of Trips}

$5,451-195,585$

Zip Codes Within Metro Area

\section{Roadway System}

MnPASS Corridor

Interstate

- MN Highway

_ US Highway

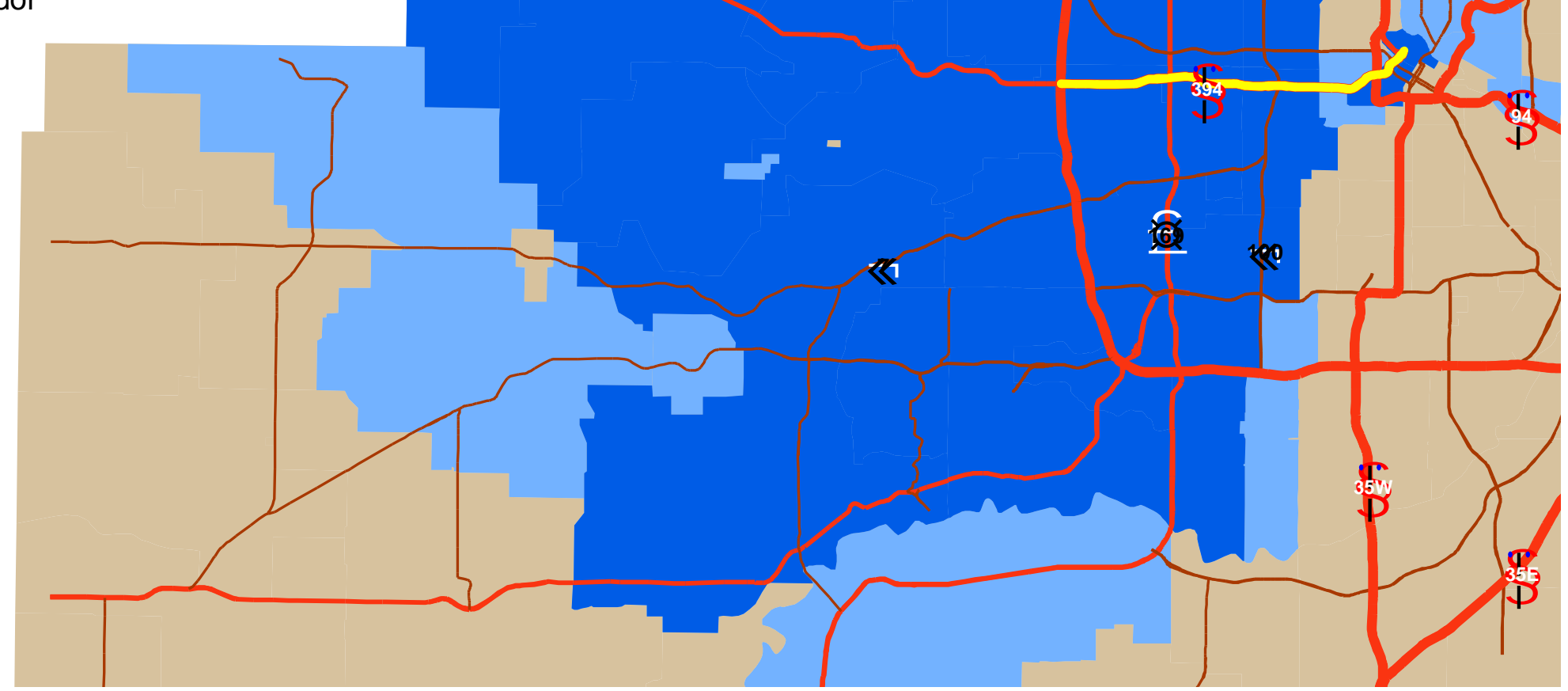

Data Source: Minnesota Department of Transportation Database, US Census 2000, Metro GIS

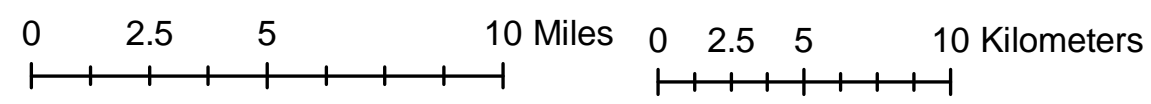

